\title{
Rho Kinase Regulates Schwann Cell Myelination and Formation of Associated Axonal Domains
}

\author{
Carmen V. Melendez-Vasquez, ${ }^{1,3}$ Steven Einheber, ${ }^{1}$ and James L. Salzer ${ }^{1,2,3}$ \\ Departments of ${ }^{1}$ Cell Biology and ${ }^{2}$ Neurology, and the ${ }^{3}$ Molecular Neurobiology Program, Skirball Institute of Biomolecular Medicine, New York University \\ School of Medicine, New York, New York 10016
}

The myelin sheath forms by the spiral wrapping of a glial membrane around an axon. The mechanisms involved are poorly understood but are likely to involve coordinated changes in the glial cell cytoskeleton. Because of its key role as a regulator of the cytoskeleton, we investigated the role of Rho kinase (ROCK), a major downstream effector of Rho, in Schwann cell morphology, differentiation, and myelination. Pharmacologic inhibition of ROCK activity results in loss of microvilli and stress fibers in Schwann cell cultures and strikingly aberrant myelination in Schwann cell-neuron cocultures; there was no effect on Schwann cell proliferation or differentiation. Treated Schwann cells branch aberrantly and form multiple, small, independent myelin segments along the length of axons, each with associated nodes and paranodes. This organization partially resembles myelin formed by oligodendrocytes rather than the single long myelin sheath characteristic of Schwann cells. ROCK regulates myosin light chain phosphorylation, which is robustly, but transiently, activated at the onset of myelination. These results support a key role of Rho through its effector ROCK in coordinating the movement of the glial membrane around the axon at the onset of myelination via regulation of myosin phosphorylation and actomyosin assembly. They also indicate that the molecular machinery that promotes the wrapping of the glial membrane sheath around the axon is distributed along the entire length of the internode.

Key words: Rho GTPases; RhoA; myelination; Schwann cell; node of Ranvier; myosin

\section{Introduction}

Myelin is a unique, multilamellar membrane sheath elaborated around axons by Schwann cells in the peripheral nervous system (PNS) and oligodendrocytes in the CNS; it is required for efficient and rapid propagation of action potentials by saltatory conduction. In vivo and in vitro studies suggest that the myelin sheath forms by progressive wrapping of an inner (adaxonal) membrane of the Schwann cell around the axon (Geren, 1954; Bunge et al., 1989). The sheath is initially loosely spiraled and later compacts; subsequently, the sheath further expands in the radial and longitudinal directions (Peters et al., 1991). Oligodendrocytes appear to first extend a filopodia along the axon and later, a ruffling lamellipodia spirals around the axon by a comparable mechanism of an inner turn wrapping around the axon (Asou et al., 1995). However, unlike Schwann cells, which form only a single myelin sheath per cell, oligodendrocytes elaborate multiple processes, each of which can independently myelinate axons; they also lack the basal lamina characteristic of PNS myelin.

Received Nov. 3, 2003; revised Feb. 14, 2004; accepted March 9, 2004.

This study was supported by National Institutes of Health Grants NS38208 and NS43474 to J.L.S. and by the Wadsworth Foundation. C.V.M.-V. was a recipient of an Advanced Postdoctoral Fellowship from the National Multiple Sclerosis Society (FA 1411-A-1). We thank Dr. Teresa Milner for assistance with electron microscopy.

Correspondence should be addressed to Dr. Carmen V. Melendez-Vasquez, Molecular Neurobiology Program, Skirball Institute of Biomolecular Medicine, New York University School of Medicine, 540 First Avenue, New York, NY 10016. E-mail:melenc02@med.nyu.edu.

S. Einheber's present address: Medical Laboratory Sciences Program, Hunter College School of Health Sciences, New York, NY 10010.

DOI:10.1523/JNEUROSCI.4920-03.2004

Copyright $\odot 2004$ Society for Neuroscience $\quad$ 0270-6474/04/243953-11\$15.00/0
These dramatic morphogenetic events are likely to reflect major changes in the organization of the glial cell actin cytoskeleton. The importance of the actin cytoskeleton was underscored by studies in which treatment of myelinating Schwann cell-neuron cocultures with cytochalasin D blocked ensheathment and myelination in a concentration-dependent manner (FernandezValle et al., 1997). Localization studies have demonstrated that actin and ERM (ezrin, radixin, and moesin) proteins, which are initially diffusely distributed, concentrate at either end of the Schwann cell just before myelination (Melendez-Vasquez et al., 2001; Pedraza et al., 2001) at tips of the cell that are dynamically active (Gatto et al., 2003). Actin microfilaments are also enriched in the processes of immature oligodendrocytes and, together with myosin IIB, are concentrated at the leading edges (Kachar et al., 1986; Wilson and Brophy, 1989; Song et al., 2001).

Rho GTPases, a family of small GTP-binding proteins, are important candidates to coordinate remodeling of the actin cytoskeleton during myelination. Rho, Rac, and Cdc42 have been the most extensively characterized family members and were originally implicated in the signal transduction pathways that control actomyosin assembly in stress fibers, lamellipodia, and filopodia, respectively. They are now known to regulate a wide variety of actin-based morphogenetic events (for review, see Etienne-Manneville and Hall, 2002). Rho GTPases are molecular switches, cycling between an inactive (GDP-bound) and an active (GTP-bound) state. In their active state, these molecules bind to a variety of effectors that regulate the actin cytoskeleton and its interaction with microtubules (Etienne-Manneville and Hall, 2002; Rodriguez et al., 2003). 
A key effector of Rho is Rho kinase (ROCK), a serinethreonine kinase that regulates actin polymerization and myosin activity (Amano et al., 2000; Tsuji et al., 2002; Riento and Ridley, 2003). ROCK has two isoforms, both of which are widely expressed in various tissues, although ROCK 2 predominates in the heart and brain (Amano et al., 2000; Riento and Ridley, 2003). After activation by Rho, ROCK phosphorylates a number of substrates that regulate cytoskeletal assembly (Amano et al., 1999). Because of the high homology of their kinase domains, these isoforms are likely to have similar substrate specificities, including the ERM proteins (Oshiro et al., 1998), LIM kinase (Maekawa et al., 1999), and adducin (Matsuoka et al., 2000). Of particular interest, ROCK directly phosphorylates myosin II light chain (MLC), a regulatory subunit (Amano et al., 1996), and inactivates its phosphatase (Kimura et al., 1996). Myosin II is a well characterized motor protein with a role in diverse motile activities including vesicle trafficking, membrane ruffling, and cell migration (Mermall et al., 1998). Phosphorylation of MLC stimulates myosin II activity and assembly, promoting the stability and contractility of actomyosin (Tan et al., 1992). MLC also can be phosphorylated directly via myosin light chain kinase (Ikebe et al., 1986) and by p21-activated kinase (PAK) (Chew et al., 1998), which are regulated in part by different upstream signals, including other Rho GTPases and $\mathrm{Ca}^{2+} /$ calmodulin (Chew et al., 1998; Tsuji et al., 2002).

Little is known about the role of the Rho GTPases during myelination. In this study, we examined the distribution of Rho and ROCK in Schwann cells and the role of the latter in myelin sheath formation. We provide evidence that ROCK plays a key role in the coordinate progression of the Schwann cell membrane around the axon during myelination by regulating MLC phosphorylation and actomyosin assembly.

\section{Materials and Methods}

Preparation of sciatic nerve sections and teased fibers. Teased fibers and frozen sections from sciatic and optic nerves were prepared as described previously (Rios et al., 2000). Briefly, sciatic nerves were removed from Sprague Dawley rats (Taconic Farms, Germantown, NY), fixed in 4\% paraformaldehyde, and teased in ice-cold Dulbecco's PBS using fine needles. For frozen sections, sciatic nerves were dissected out, fixed in $4 \%$ paraformaldehyde, cryoprotected in 30\% sucrose, frozen in OCT (VWR Scientific Products New York, NY), and cut in $10 \mu \mathrm{m}$ thick cryostat sections. Tissue slides were stored at $-80^{\circ} \mathrm{C}$ until used.

Tissue culture methods. Primary rat Schwann cells, dorsal root ganglion (DRG) neurons, and myelinating Schwann cell-DRG coculture were established as described previously (Einheber et al., 1995). Schwann cell cultures were kept in serum-containing media (D media) consisting of DMEM (BioWhittaker, Walkersville, MD), 10\% FBS (Hyclone Laboratories, Logan, UT), and $2 \mathrm{~mm}$ L-glutamine (Invitrogen, Gaithersburg, MD) until used. For ROCK inhibition experiments, Schwann cell cultures were treated for $24 \mathrm{hr}$ with D media containing Y-27632 (Welfide Corporation, Osaka, Japan) or HA-1077 (Calbiochem, La Jolla, CA) at a final concentration of $10 \mu \mathrm{M}$. For studies of the effects of ROCK inhibition on myelination, cocultures were switched to myelin-promoting media and supplemented with or without Y-27632 or HA-1077 at a final concentration of $20 \mu \mathrm{m}$. Control and treated cultures were allowed to myelinate for up to 3 weeks.

To quantitate the extent of myelination in control and ROCKinhibited cultures, the total number and length of myelin basic protein $(\mathrm{MBP}+)$ segments was counted in each of nine random low-power fields per coverslip (total of 18 fields per condition per experiment; total of two experiments). Statistical tests were performed using Graph Pad Prism software (Graph Pad, San Diego, CA)

Antibodies and immunofluorescence. Antibodies used in these studies included those reactive to: Rho A (s.c.-418), Rock-1 (s.c.-6056), Rock-2 (s.c.-6056), Krox-20 (s.c.-190), and Krox-24 (s.c.-110) (Santa Cruz Bio- technology, Santa Cruz, CA); phosphorylated cofilin and phosphorylated myosin light chain 2 (Cell Signaling Technology, Beverly, MA); monoclonal antibody (mAb) against MBP (SMI 94; Sternberger Monoclonals, Baltimore, MD); phalloidin-FITC and rabbit anti-EHS laminin Ab (Sigma, St. Louis, MO); a rat mAb (297S) specific for the 567Tphosphorylated forms of ERM proteins (S. Tsukita, Kyoto University, Kyoto, Japan); rabbit polyclonal antibodies against human placental ezrin and recombinant rat glutathione $S$-transferase-radixin (A. Bretscher, Cornell University, Ithaca, NY); guinea-pig antiserum to the carboxy terminus of mouse Neurexin IV/Caspr (M. Bhat, University of North Carolina, Chapel Hill, NC); chicken Ab to $\beta \mathrm{IV}$ spectrin (M. Komada, Tokyo Institute of Technology, Tokyo, Japan), and rabbit polyclonal antibodies to P0 (M. Filbin, Hunter College, New York, NY) and SCIP (G. Lemke, The Salk Institute, La Jolla, CA). Secondary antibodies conjugated to Rhodamine, fluorescein, coumarin, or cyanin 5 were obtained from Jackson Laboratories (West Grove, PA). Fixed samples (Schwann cells, myelinating coculture, frozen sections, and teased sciatic nerves) were permeabilized with acetone at $-20^{\circ} \mathrm{C}$, washed, and stained as described previously (Melendez-Vasquez et al., 2001). The tissue was examined by epifluorescence on a Zeiss (Thornwood, NY) Axiophot microscope and on a Zeiss LSM 510 confocal microscope.

Schwann cell proliferation assays. To investigate the effect of ROCK inhibition on the proliferation of Schwann cells, bromodeoxyuridine (BrdU) incorporation assays were performed as described previously (Maurel and Salzer, 2000). Briefly, 50,000 Schwann cells were plated onto poly-L-lysine-coated glass coverslips, and the next day were treated for $24 \mathrm{hr}$ with 10 or $20 \mu \mathrm{M}$ Y-27632 or HA-1077 in fresh media. Control cultures were maintained in media with or without forskolin ( $4 \mu \mathrm{m}$; Sigma) and glial growth factor (GGF) (5 ng/ml; rhGGF2). We also examined Schwann cells proliferating in cocultures with DRG neurons. For these studies, 10,000 Schwann cells in C media were seeded onto dissociated DRG neurons. After $24 \mathrm{hr}$, cultures were fed fresh media with or without ROCK inhibitors for an additional $24 \mathrm{hr}$. Cells were then processed for BrdU immunostaining. In all conditions, BrdU was added during the last $4 \mathrm{hr}$ of culture at a final concentration of $20 \mu \mathrm{M}$; immunostaining was performed according to the instructions of the manufacturer (Boehringer Mannheim, Indianapolis, IN).

Electron microscopy. Control and treated myelinating cocultures were processed as described previously (Einheber et al., 1995) or by a "stamp" method. For the latter, cultures grown on collagen-coated glass coverslips were rinsed in PBS and fixed overnight at $4^{\circ} \mathrm{C}$ in $2 \%$ glutaraldehyde diluted in $0.1 \mathrm{M}$ phosphate buffer, pH $7.0(0.1 \mathrm{M} \mathrm{PB})$. The fixed cultures were then washed in $0.1 \mathrm{M} \mathrm{PB}$ and incubated in $2 \%$ osmium tetroxide in $0.1 \mathrm{M}$ PB for $1 \mathrm{hr}$. After washing in $0.1 \mathrm{M} \mathrm{PB}$, the cultures were dehydrated through a graded series of alcohol ranging from 30 to $100 \%$ and then incubated with EMbed (Electron Microscopy Sciences, Fort Washington, PA) for $2 \mathrm{hr}$. The EMbed was removed, and capsules filled with EMbed were then inverted on top of each coverslip and allowed to sit overnight. The coverslips with inverted capsules were incubated for $2 \mathrm{~d}$ at $60^{\circ} \mathrm{C}$ to polymerize the resin. The capsules bearing the embedded cultures were then pried from the coverslips, and ultrathin sections were prepared from regions of interest. The sections were counterstained with uranyl acetate and Reynold's lead citrate and examined on a Philips (Eindhoven, The Netherlands) CM10 electron microscope.

Cell extracts and immunoblotting. Rat sciatic nerves, cultures of DRG neurons, Schwann cells, and myelinating cocultures were lysed in a solution containing 1\% SDS, $150 \mathrm{~mm} \mathrm{NaCl}, 10 \mathrm{~mm}$ EDTA, $1 \mathrm{~mm}$ PMSF, 10 $\mu \mathrm{g} / \mathrm{ml}$ aprotinin, and $20 \mu \mathrm{M}$ leupeptin in $50 \mathrm{~mm}$ Tris, $\mathrm{pH}$ 7.4. Lysates were cleared by centrifugation at $12,000 \times g$ for $10 \mathrm{~min}$. Protein concentrations were determined using the BCA method (Pierce, Rockford, IL). Lysates $(10-30 \mu \mathrm{g}$ of total protein) were subjected to SDS-PAGE and blotted onto nitrocellulose. Appropriate regions of the blots were cut and incubated with specific antibodies and developed using the SuperSignal chemiluminescent substrate (Pierce).

\section{Results}

\section{Expression of Rho and ROCK in Schwann cells in vitro and} in vivo

We first examined the distribution and expression of Rho and ROCK in Schwann cells by immunofluorescence and Western 


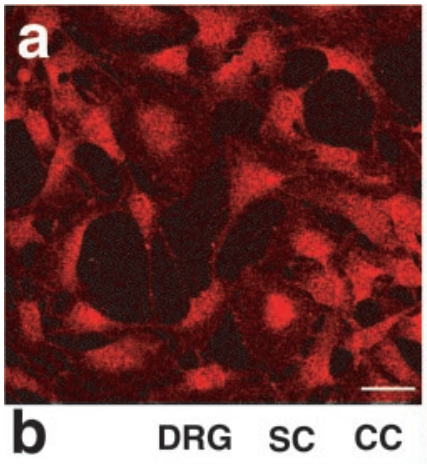

RhoA

ROCK1

ROCK2

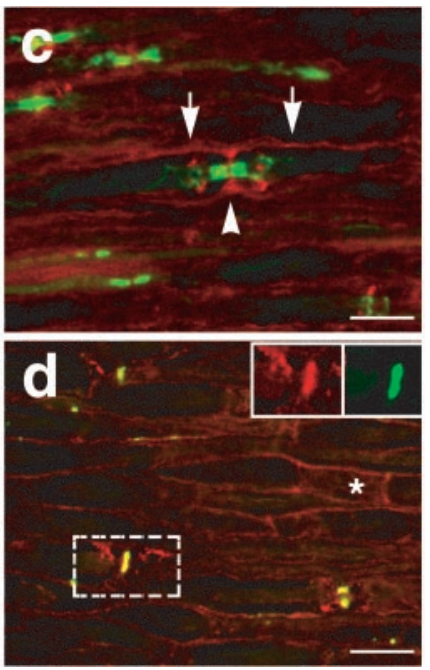

Figure 1. Expression of Rho by Schwann cells in vitro and in vivo. $a$, Primary cultures of rat Schwann cells demonstrate perinuclear and cytoplasmic expression of Rho (red). Scale bar, 30 $\mu \mathrm{m} . b$, Western blotting of Rho and both isoforms of ROCK in lysates of DRG neurons, Schwann cells (SC), and myelinating cocultures (CC). c, Teased fibers of adult rat sciatic nerve stained for Rho (red) and Caspr (green). Rho is present in the Schwann cells in the abaxonal (arrows) membrane, at the node of Ranvier (arrowhead), and some juxtaparanodes. $d$, Sciatic nerve section stained for Rho (red) and ezrin (green), which colocalize (yellow) in the nodal Schwann cell microvilli (inset). Rho was also detected at the Schmidt-Lanterman incisures (asterisks). Scale bars: $c, d, 15 \mu \mathrm{m}$.

blotting (Fig. 1). ROCK has two known isoforms, ROCK1 and ROCK2, which are widely expressed (Amano et al., 2000; Riento and Ridley, 2003). We found Rho to be diffusely expressed in the cytoplasm of primary cultures of rat Schwann cells (Fig. 1a). In cocultures of neurons and Schwann cells, Rho and both ROCK isoforms were robustly expressed by Schwann cells relative to neurons under premyelinating and myelinating conditions (data not shown). These results were corroborated by Western blotting (Fig. 1b), which demonstrated that Schwann cells express high levels of Rho, ROCK1, and ROCK2, whereas DRG neurons express lower but detectable levels of RhoA and ROCK2. These results agree with a recent report that cultured rat Schwann cells express high levels of RhoA and RhoB (Taylor et al., 2003). In adult rat sciatic nerve, RhoA staining was seen in various Schwann cell compartments, principally in the abaxonal membrane and nodal microvilli (Fig. 1c). Colocalization with ezrin, which is highly expressed in the Schwann cell microvilli, provided additional evidence that Rho is enriched at this site (Fig. 1d). Rho was also detected at the Schmidt-Lanterman incisures (Fig 1c,d). These are sites of noncompacted membrane and actin enrichment (Trapp et al., 1989), perhaps indicating active regulation of the actin cytoskeleton in these regions. Preliminary analysis suggests that Rho is diffusely expressed in Schwann cells at the onset of myelination (e.g., P2) in peripheral nerves (data not shown). Together, these results demonstrate that Rho and ROCK expression is primarily associated with Schwann cells in cultures and in the PNS.

\section{Changes in Schwann cell morphology with inhibition of ROCK}

To study the role of Rho and its effector ROCK on Schwann cell morphology, we used two selective inhibitors of this kinase, Y-27632 and HA-1077. Both drugs have an affinity for Rho kinases that is at least 20-30 times higher than those for other Rho effector kinases, including citron kinase and protein kinase $\mathrm{N}$,

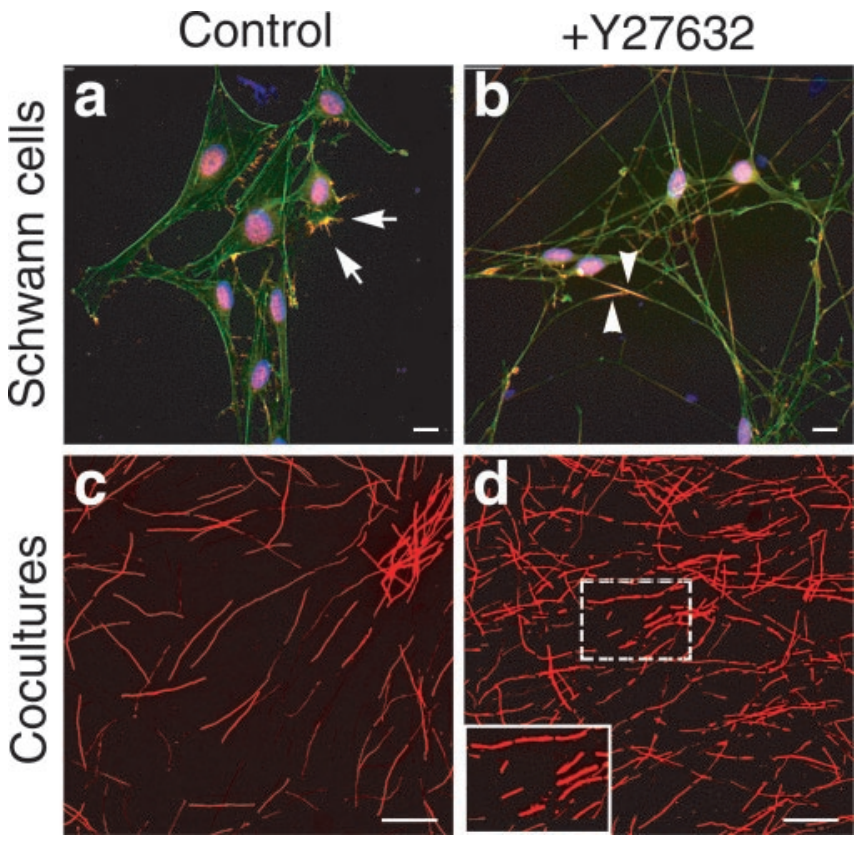

Figure 2. Altered Schwann cell morphology and myelination with ROCK inhibition. $a, b$, Primary Schwann cell cultures, untreated $(a)$ or after $24 \mathrm{hr}$ of treatment $(b)$ with $10 \mu \mathrm{m}$ Y-27632, were stained with phalloidin FITC (green), radixin antibodies (red), and the Hoechst stain (blue). Treated Schwann cells show dramatic changes in actin cytoskeleton organization, including loss of stress fibers and microvilli ( $a$, arrows). Treated Schwann cells developed multiple filopodia-like processes with segments enriched in radixin along their length $(b$, arrowheads). Scale bars, $15 \mu \mathrm{m}$. c, $d$, Schwann cell-neuron cocultures were maintained for $7 \mathrm{~d}$ in myelinating media without (c) or with (d) Y-27632 and stained for MBP (red). Inhibition of ROCK at the onset of myelination resulted in the formation of large numbers of short and some abnormally thick myelin segments ( $d$, inset). Scale bars, $50 \mu \mathrm{m}$.

and have been extensively used to study the function of ROCK (Davies et al., 2000; Ishizaki et al., 2000). Schwann cells were treated with or without Y-27632 or HA-1077 for $24 \mathrm{hr}$ at a final concentration of $10 \mu \mathrm{M}$. At low density, Schwann cells in control cultures exhibited a flattened, polygonal morphology with abundant stress fibers and numerous radixin-positive microvilli protruding from their surface (Fig. 2a). Schwann cells treated with Y-27632 (Fig. 2b) or HA-1077 (data not shown) were significantly more elongated, with collapsed stress fibers, and had lost their microvilli; radixin staining was instead present within filopodial-like processes at either end of the cell (Fig. $2 b$, arrowheads). Similar changes were also observed at a higher drug concentration $(20 \mu \mathrm{M})$ but within a shorter period of time (30 min). At longer incubation periods (up to $48 \mathrm{hr}$ ), Schwann cells rounded up and detached from the substrate (data not shown). These morphological changes are consistent with the loss of Rho activity in treated cultures, because stress fiber formation and focal adhesion complexes, which promote substrate attachment, are known to be dependent on its function (Etienne-Manneville and Hall, 2002).

\section{Schwann cells form numerous short myelin segments in ROCK-inhibited cocultures}

We next characterized the effects of ROCK inhibition on Schwann cell-axon interactions in myelinating cocultures. Schwann cells were added to dissociated DRG neuron cultures with established and extensive neurite outgrowth. Cocultures were then switched to media containing ascorbate to rapidly promote basal lamina formation and myelination with or without 20 $\mu \mathrm{M}$ Y-27632 or HA-1077 for 1 week. The drug was well tolerated 
Table 1. Quantitation of the effects of ROCK inhibition on myelination

\begin{tabular}{lcccc}
\hline & Control 4 d & Treated 4 d & Control 7d & Treated 7d \\
\hline Total number of segments & $112 *$ & $327 *$ & $782 *$ & $2035 *$ \\
Mean segment length $(\mu \mathrm{m})$ & $92 *$ & $45 *$ & $106 *$ & $48 *$ \\
SD & 39 & 26 & 41 & 29 \\
SE & 3.7 & 1.5 & 1.5 & 0.64 \\
Total myelin length & 10304 & 12426 & 82892 & 81400 \\
\hline
\end{tabular}

Schwann cell-neuron cocultures were maintained in the absence (control) or presence of $20 \mu \mathrm{M} Y-27632$ for 4 or $7 \mathrm{~d}$ and were fixed and stained for MBP. The total number of segments and mean segment length were counted and quantitated from random low-power microscopic fields in each condition. Total myelin lengths formed per culture were calculated by multiplying the total number of segments and the mean segment length. The number of segments and mean segment length differed significantly between control and treated cultures ( $* p<0.0001$; Mann Whitney $t$ test).

by the cultures at this concentration for the duration of the experiment, and it did not interfere with the attachment of Schwann cells to neurites presumably reflecting distinct mechanisms of adhesion to neurites than to the substrate (Salzer, 1995). Cultures were fixed and stained for MBP to identify compact myelin sheaths.

Two striking and reproducible effects were observed in the treated cultures: a dramatic increase in the number of myelin segments and a substantial decrease in the length of these segments compared with controls. (Fig. $2 c, d$ ). Myelin thickness appeared to be normal in many cases, but some segments in the treated cultures were abnormally thick, particularly for their short length (Fig. $2 d$, inset). Although both inhibitors had similar effects, Y-27632 generally produced more robust effects at equivalent doses and was used in most of the subsequent studies. Inhibition of ROCK has been shown to affect neurons (for example, promoting neurite outgrowth) (for review, see Luo 2002). We therefore also examined whether $20 \mu \mathrm{M}$ Y-27632 had any effect on mature DRG cultures, which had already developed an extensive neurite network before exposure to the drug. After 1-2 weeks of continuous treatment, no effect on neurite morphology or branching was observed in treated cultures compared with controls by phase microscopy or staining with anti-neurofilament antibodies (data not shown).

Quantitation of the number and length of MBP segments in these cultures demonstrated that there was approximately three times as many $\mathrm{MBP}+$ segments in ROCK-inhibited versus control cultures, and that treated segments were on average $50-60 \%$ shorter than control segments. Each of these differences was highly significant $(p<0.0001)$ (Table 1$)$. Although some myelin segments of normal size did form in the treated cultures, the overall size distribution in these cultures was markedly skewed toward shorter segments, whereas a normal Gaussian distribution was observed in control cultures (Fig. $3 a$ ). Remarkably, some of the segments formed in the treated cultures were shorter than $10 \mu \mathrm{m}$ (see below), a feature never observed in control cultures (Fig. 3a). These differences between control and treated cultures did not result from a delay in the onset of myelination or delayed elongation of segments because after 3 weeks of treatment, these differences persisted, and segment size remained short (Fig. $3 b$ ).

We next examined whether there is a critical window for the effects of ROCK inhibition on myelination. To this end, we added Y-27632 at different times after switching the cultures to myelinpromoting media. Adding the drug during the first $48 \mathrm{hr}$ produced the most dramatic effects in terms of the number of short $\mathrm{MBP}+$ segments present in cultures after 7-14 d. Adding the drug to cultures that had initiated myelination for $4 \mathrm{~d}$ or more had a negligible effect on myelination. Most segments that formed under these conditions had a normal appearance, and only occasional short $\mathrm{MBP}+$ segments were observed (data not shown). Interestingly, cocultures treated for $7 \mathrm{~d}$ and then maintained for an additional 1-2 weeks without the drug contained a mixture of short and normal size myelinated segments (data not shown). These results indicate that the morphological effects of ROCK inhibition on myelination (i.e., formation of aberrantly short myelin segments) are persistent; however, once the inhibition is removed, new segments that form are of normal size. Together these results suggest that ROCK activity is critical at early stages of myelination; however, once the myelination program is well established, inhibition of ROCK has no apparent effect on myelin morphology.

\section{Schwann cell proliferation and differentiation are not affected by ROCK activity}

This increase in the number of short myelin segments in the ROCK-inhibited cocultures could potentially reflect an increase in the number of Schwann cells that differentiate and form myelin coupled with a failure of these cells to elongate along the axon properly. Alternatively, changes in myelin morphology resulting from ROCK inhibition might reflect abnormalities in the organization of the myelinating Schwann cell cytoskeleton. We therefore investigated whether ROCK inhibition affected either Schwann cell proliferation or differentiation. Treatment with Y-27632 or HA-1077 had no effect on the proliferation rate of Schwann cells grown alone or stimulated to divide by coculture with neurons (data not shown), in agreement with previous reports in other systems (Ishizaki et al., 2000). In addition, Schwann cell density was comparable in control and treated cocultures on the basis of inspection of the numbers of nuclei.

ROCK inhibition also did not affect the amount of myelin that formed or Schwann cell differentiation. Thus, the total length of myelin formed per culture (i.e., the total number of segments multiplied by their mean length) was comparable in the treated and control cultures (Table 1). Analysis of P0 and myelinassociated glycoprotein (MAG) content by Western blotting was also similar in control and cultures treated for different time periods (Fig. 3c). We also examined the expression of laminin $\alpha-2$ and $\beta 1, \beta 4$ integrins in cocultures, because interactions of Schwann cell receptors with the extracellular matrix are critical in differentiaton and myelination (Previtali et al., 2001). No differences were observed in the total amount of laminin $\alpha-2$ (Fig. 3c) or $\beta 1$ and $\beta 4$ integrin subunits between control and treated cultures (data not shown). Finally, no effect on the expression of Krox 24, a transcription factor associated with nonmyelinating Schwann cells (Topilko et al., 1997) or of SCIP and Krox 20, two promyelinating transcription factors (Zorick et al., 1996), were observed by immunofluorescence (data not shown) or Western blotting (Fig. 3d). Thus, ROCK does not regulate Schwann cell differentiation or proliferation.

\section{ROCK regulates the organization of myelin segments and associated axonal domains}

To examine the morphology of individual myelinating Schwann cells in more detail, we stained cocultures for MBP and laminin, a component of the basal lamina, which delineates individual axon-Schwann cell units (Fig. 4). This analysis revealed number of significant defects in treated cultures. Notably, Schwann cells in the treated cultures frequently formed several myelin segments per cell; many of these segments were quite short (Fig. $4 c-g$ ). Thus, instead of a single, long, myelin segment characteristic of controls (Fig. 4a,b), several smaller myelin segments formed. The number of segments formed by treated Schwann cells varied. In some cases, only one (Fig. $4 e$, arrow) or two segments (Fig. $4 c$, 
a

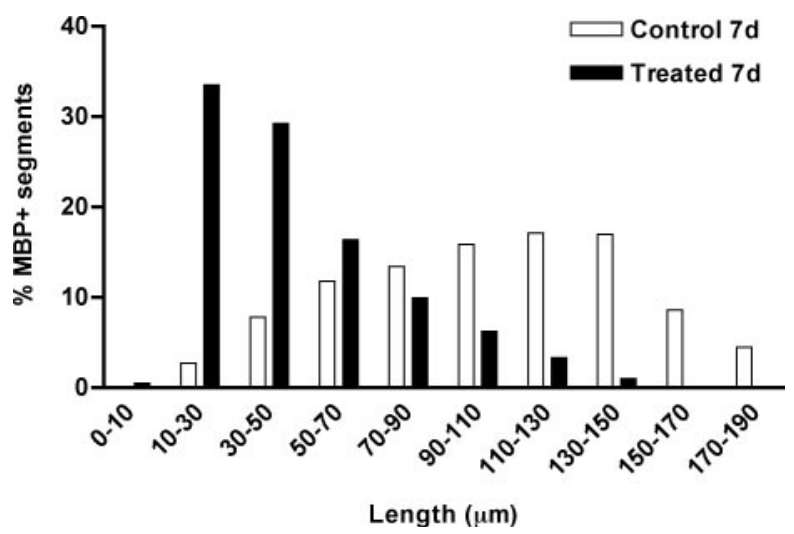

b

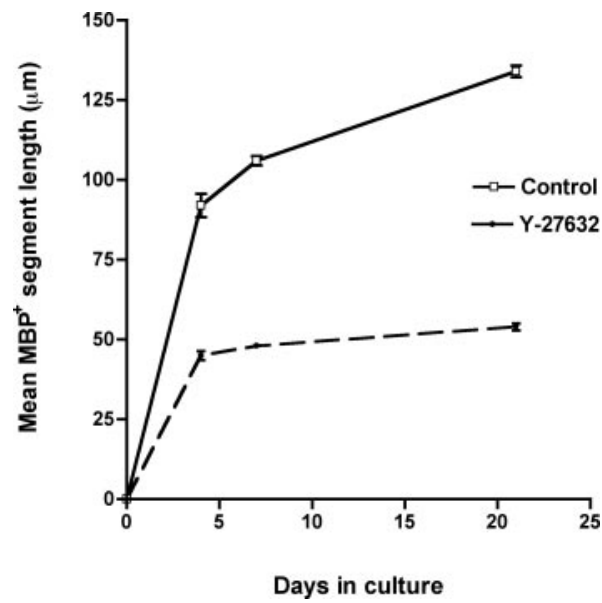

C

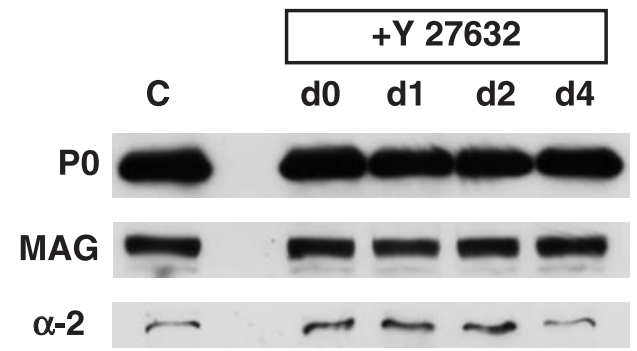

d

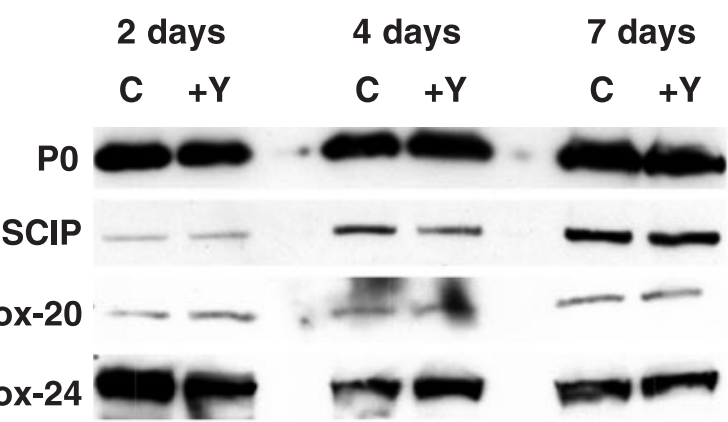

Figure 3. Effects of ROCK inhibition on myelination and differentiation. $a$, Size distribution of MBP + segments in control and treated cultures after $7 \mathrm{~d}$ in myelinating media. In ROCKinhibited cultures, the distribution is markedly skewed toward short segments. b, Quantitation of the length of MBP + segments that formed in cocultures treated with a ROCK inhibitor $(\mathrm{Y}-27632)$ at the times shown. Myelin segments were approximately one-third the length of those in control cultures even after 3 weeks in culture; data in the graph represent mean \pm SEM. c, Cocultures were treated continuously with $20 \mu \mathrm{m} \mathrm{Y-27632} \mathrm{beginning} \mathrm{at} \mathrm{different} \mathrm{times} \mathrm{(days}$ arrowheads) were generated. These short segments often formed in the central region of the cell and were typically adjacent to nonmyelinated (MBP-) regions of the same Schwann cell (Fig. $4 d-g)$. They are likely to correspond to some of the segments shown at higher power in Figure $2 d$. When several myelin segments were elaborated by a single Schwann cell, segments could vary in their apparent thickness (Fig. $4 e-g$, compare segment 1 with segments 2 and 3), strongly suggesting that each of these segments wrap around the axon independently. The overall length of myelinating Schwann cells (e.g., their extension along the axon) (indicated by the dotted lines in Fig. $4 b, d-g$ ) appeared to be unaffected by treatment and was comparable with control cultures.

Other abnormalities in the treated cultures included numerous small filopodial-like protrusions emanating from the outer surface of the myelin segment (Fig. $4 d, f, g$ ). Segments in control cultures are smooth and devoid of such protrusions along their length. In addition, in the treated cultures, Schwann cell nuclei were often eccentrically located along the longitudinal axis of myelinating cells (Fig. $4 d$,f, asterisks), whereas in controls, nuclei are invariably at the center of the internode (Fig. $4 b$, asterisks).

We characterized the ultrastructure of these short myelin segments by electron microscopy (Fig. 5). In agreement with immunofluorescence results, we identified a number of very short compact myelin segments, each complete with normally arrayed paranodal loops contacting the axon. In the example shown in Figure $5 a$, a remarkably short internode of 3-4 $\mu \mathrm{m}$ with two flanking paranodal regions at either end is shown. Other abnormalities of myelination included double paranodes (Fig. $5 b$ ), which are likely to result from some inner myelin lamellae that terminate within the internode (PN1), rather than extending the full length of the sheath along the axon. In addition, atypical Schwann cell processes were frequently present. Figure $5 c$ (inset magnified in $d$ ) shows a short process arising from an adjacent nonmyelinating Schwann cell, contacting the paranodal and nodal regions of another segment. These panels also demonstrate two nodes (labeled $\mathrm{N}$ in Fig. $5 b$; delineated by arrowheads in $d$ ), both of which are contacted by overlying Schwann cell processes.

To determine the effects of ROCK inhibition on the molecular organization of myelinated fibers, we characterized the distribution of nodal ( $\beta \mathrm{IV}$ spectrin and $\mathrm{Na}^{+}$channels) and paranodal (Caspr) markers in the treated cultures. Nodal (Fig. 6a) and paranodal (Fig. 6b-d) markers were enriched on either side of these short MBP + myelin segments. As a result, a single Schwann cell organized up to four such nodal-paranodal domains along its territory (Fig. 6a,b, arrows). These nodal domains were consequently much more closely spaced than in controls. These findings and the different thickness of segments from a single cell strongly suggest that short $\mathrm{MBP}+$ segments form as independent myelin sheaths around axons. Caspr and nodal markers were typically present just beyond the ends of compact MBP + myelin segments, as observed in control cultures (data not shown). In a few instances, Caspr staining overlapped with that of MBP (Fig. $6 c$, arrowhead), indicating that a portion of the inner myelin lamellae terminated prematurely as paranodal loops (compare

$\leftarrow$

0 -4) after the initiation of myelination and allowed to myelinate for $11 \mathrm{~d}$. Lysates were prepared and analyzed by blotting for P0, MAG, and the $\alpha$ - 2 chain of laminin. The expression of these myelin-related markers in treated cultures was similar at all times to that in control cultures (C). d, Lysates from control (C) or ROCK-inhibited $(+Y)$ cocultures treated for 2, 4, or $7 \mathrm{~d}$ were analyzed for expression of P0, SCIP, Krox-20, and Krox-24; levels were unchanged between treated cultures and control cultures at all time points sampled. 
with PN1) (Fig. 5b). Because the distribution of axonal domains in the ROCKinhibited cultures mirrored abnormalities of the myelin sheaths, these findings support the notion that the glial cell dictates the distribution of axonal components. In agreement, components of the initial segments, which are intrinsically specified by the neuron (Winckler et al., 1999), were unaffected in treated cultures (data not shown).

As noted, myelinating Schwann cells in the treated cultures branched aberrantly with processes arising from the outer surface of one myelin segment contacting the paranodes of another myelinated fiber (Fig. $6 c, d$, asterisks); these findings are consistent with EM results described above (Fig. 5c). Remarkably, in one instance, an orthogonal branch from the surface of a myelinating Schwann cell appeared to form a thin myelin sheath around an entirely separate axon (Fig. $6 d$, arrow). Each end of this short myelin segment is associated with paranodes (compare with Fig. $5 a$ ).

Given the effect of ROCK inhibition on ERM distribution and microvillar formation in Schwann cell-only cultures (Fig. $2 b$ ), we examined the distribution of ERM proteins in cocultures treated with Y-27632 (Fig. 7). In control cocultures, ezrin was clearly concentrated at the ends of myelinated segments (Fig. 7a,c,e, arrowheads) overlying the nodal axolemma as reported previously (Melendez-Vasquez et al., 2001). Colocalization of ezrin with $\beta \mathrm{IV}$ spectrin at the node (Fig. 7e, arrowheads) is also shown. In ROCK-inhibited cultures (Fig. $7 b, d, f$ ), the distribution of ezrin was aberrant and frequently persisted along much of the length of the Schwann cell (Fig. 7d). However, ezrin staining also was detected often at nodes (Fig. $7 b, d, f$, arrowheads) where it colocalized in most cases with spectrin (Fig. $7 f$ ). These results indicate that development of longitudinal polarity, evidenced by the distribution of ezrin, is perturbed in the ROCK-inhibited cultures. Together, these morphological and immunofluorescence studies demonstrate that inhibition of ROCK promotes aberrant branching, results in the multicentric formation of myelin segments with matching abnormalities of axonal domains, and perturbs longitudinal polarity.

\section{ROCK regulates myosin light chain phosphorylation}

To elucidate the mechanisms by which ROCK regulates myelin sheath formation and might perturb ERM localization, we examined phosphorylation levels of several presumptive targets of ROCK by Western blotting (Fig. 8a). Surprisingly, despite its altered distribution, levels of ERM phosphorylation were similar in control and treated cocultures; phosphorylation levels even increased in the Schwann cell-only cultures (data not shown).
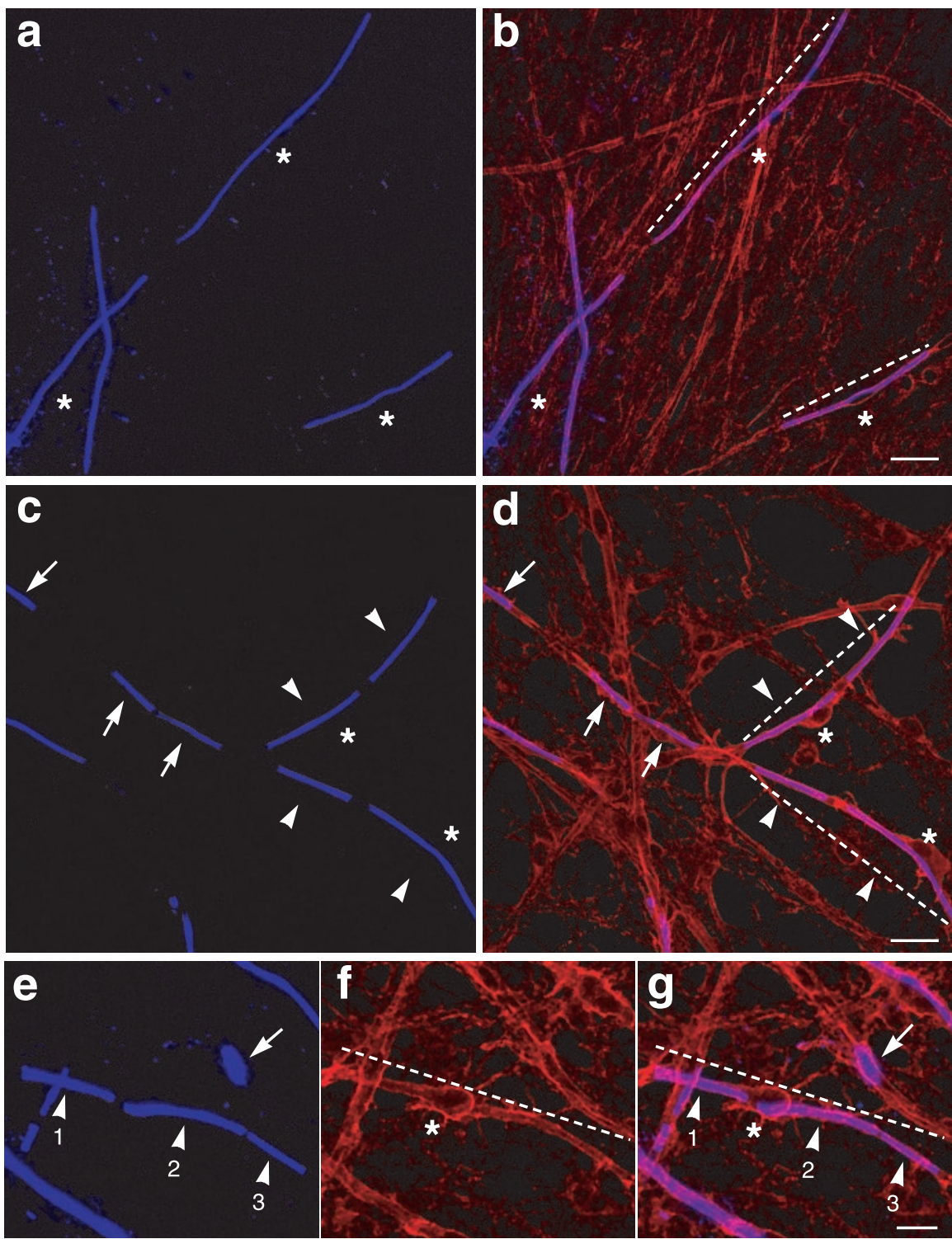

Figure 4. ROCK regulates branching and myelin sheath organization. Myelinated cocultures were stained with antibodies to MBP (blue) and laminin (red), which delineates the basal lamina surrounding each axon-Schwann cell unit (dashed lines). In control cultures $(a, b)$, Schwann cells elaborate a single long internode. In treated cultures $(c-q)$, individual Schwann cells fre(arrowheads). Many of these segments were quite short and comprised only a portion of a single Schwann cell (delineated in $f$ with laminin antibodies) exhibit variation in their thickness (compare segments 1 and 3). Asterisks indicate the position of the Schwann cell nuclei along the internode. In control cultures $(a, b)$, the nucleus is at the center of the internode, whereas in treated cultures $(d, f)$, it is displaced. Scale bars: $a-d, 25 \mu \mathrm{m} ; e-g, 10 \mu \mathrm{m}$.

These results indicate that phosphorylation of ERMs in Schwann cells is primarily independent of ROCK activity, in agreement with a previous report (Matsui et al., 1999), and suggest that the altered distribution of ezrin reflects aberrant Schwann cell morphology or cytoskeletal organization rather than changes in ERM phosphorylation levels. We also examined two additional downstream targets of ROCK involved in actin cytoskeleton organization: MLC, the phosphorylation levels of which are directly regulated by ROCK; and cofilin, which is phosphorylated by LIM-kinase, a substrate of ROCK (Maekawa et al., 1999) and of PAK (Edwards et al., 1999). The levels of phosphorylated MLC but not cofilin were substantially reduced in cocultures treated with ROCK inhibitor. Some residual MLC phosphorylation persists, which may reflect activity of ROCK-independent pathways including MLC kinase. 

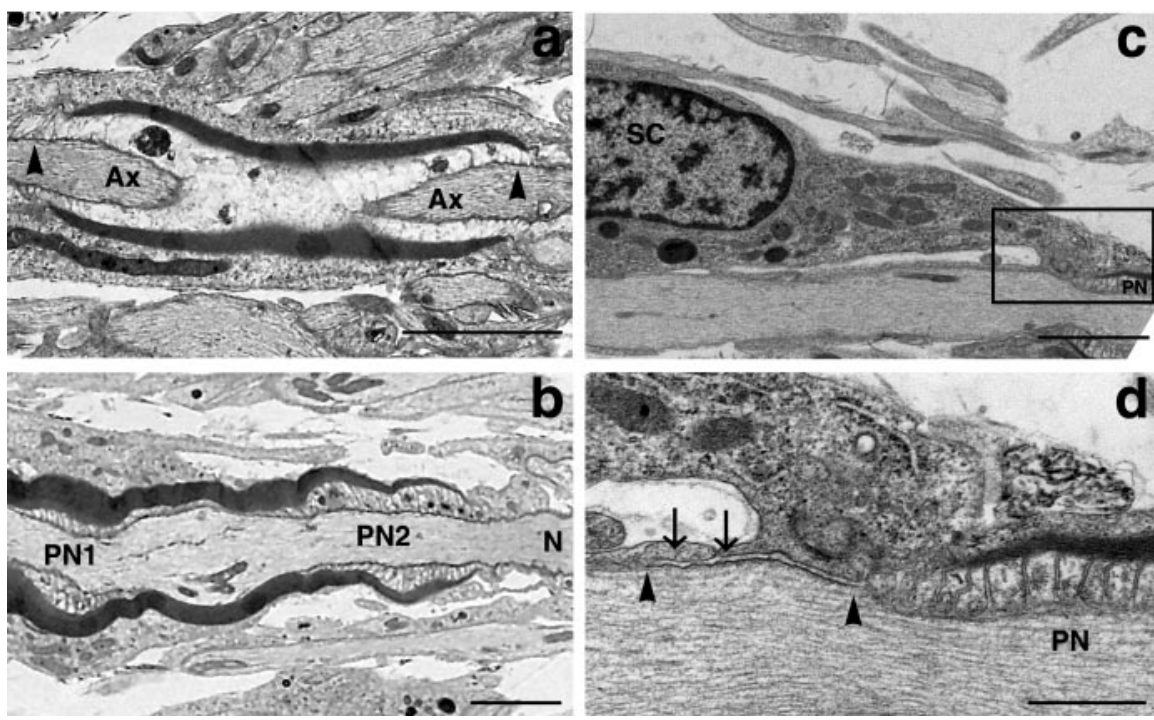

Figure 5. Abnormalities in the ultrastructure of myelin in treated cultures. Examples of abnormalities in myelin sheath formation in cocultures maintained for 3 weeks in the presence of Y-27632 are shown. $a$, An example of a very short, compact myelin segment that formed in ROCK-inhibited cultures. Arrowheads indicate paranodal loops contacting the axon ( $\mathrm{Ax}$ ) at each end; the central portion of the axon is from the plane of the section. The length of this segment, including both paranodal regions, is $6-7$ $\mu \mathrm{m} . b$, Two paranodes of a single myelin sheath are shown; PN1 is an internal paranode. Schwann cell processes contacting the node (N) are also present. c, A nonmyelinating Schwann cell extends a process that contacts the paranodal region (PN) of an adjacent fiber. $d$, Inset from $c$ at higher magnification demonstrates that smaller finger-like process (arrows) arising from this intervening $S c h w a n n$ cell also contact the adjacent nodal axolemma identified by the dense membrane undercoating (delineated by arrowheads). Scale bars: $a-c, 2 \mu \mathrm{m} ; d, 500 \mathrm{~nm}$.
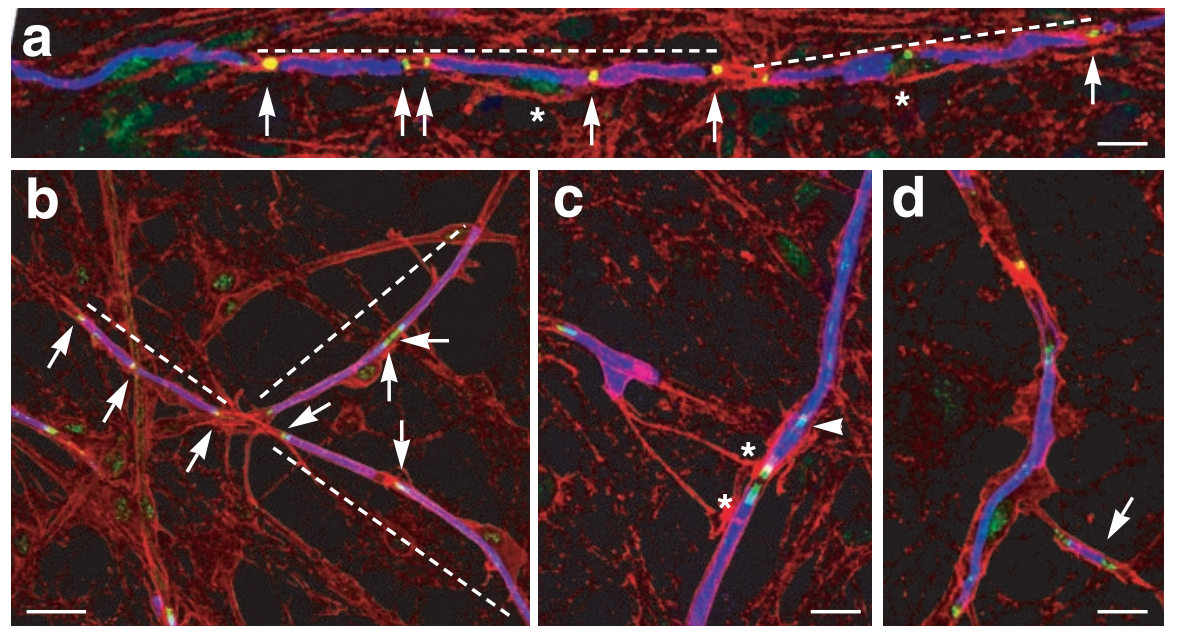

Figure 6. Schwann cells form multiple nodes and paranodes in treated cultures. $a-d$, Cocultures were treated with the HA-1007 ( $a)$ or Y-27632 ( $b-d)$ inhibitors and stained $(a-d)$ with antibodies to MBP (blue), laminin (red), and $\beta$ IV spectrin ( $a$ green) and Caspr ( $b-d$, green). Arrows indicate nodes $(a)$ and paranodes $(b-d)$ that are formed by individual Schwann cells (indicated by dashed lines). Asterisks in a indicate the location of the Schwann cell nucleus. c, Processes arising from the abaxonal surface of a myelinating Schwann cell (with an unusual sheath) are delineated by laminin staining and project to the paranodal regions of another myelinated fiber. $d$, An orthogonal branch of one myelinating Schwann cell appears to form a short myelin segment (indicated by an arrow) around an entirely distinct axon with paranodes at each end. Scale bars: $a, 12.5 \mu \mathrm{m} ; b, 25 \mu \mathrm{m}$; $c, d, 10 \mu \mathrm{m}$.

These results suggest that MLC phosphorylation may play a key role in ROCK-dependent events at the onset of myelination. To further explore this possibility, we examined the levels of phosphorylated MLC during peripheral nerve development (Fig. $8 b)$. MLC phosphorylation is dramatically upregulated at the onset of myelination in rat sciatic nerve, which begins in a near synchronous manner at postnatal day 1 (P1) to P2 (MelendezVasquez et al., 2001). The level of phosphorylated MLC decreases

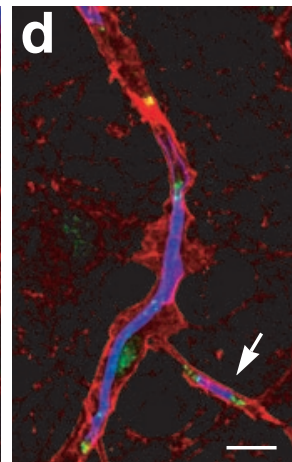

substantially after $\mathrm{P} 2$, and minimal signal is detected in the adult nerve. Initial results with antibodies to phospho-cofilin suggest a very similar pattern of activation (data not shown). In contrast, myelin protein expression progressively increases during the same time period; actin levels, used as a loading control, were equivalent at each time point. Because both neurons and Schwann cells could contribute to the phospho-MLC activity detected on the blots, we examined nerves by immunofluorescence. These results confirmed highlevel expression of phospho-MLC in Schwann cells at P2 (data not shown). Initial studies indicate that ROCK levels either gradually increase (ROCK1) or remain stable (ROCK2) from birth through P30, suggesting that MLC phosphorylation is independent of the levels of ROCK proteins (data not shown). Together, these results suggest that MLC is actively phosphorylated by ROCK at the onset of myelination and plays a key role in establishing the morphological organization of the myelin sheath.

\section{Discussion}

Although the function of the myelin sheath in saltatory conduction (Huxley and Stämpfli, 1949) and important details of its structure (Geren, 1954) have long been known, the molecular mechanisms of its formation have remained elusive. With this report, we established a novel role for ROCK, a key effector of Rho, in myelin sheath formation by Schwann cells. Our findings indicate that ROCK, which appears to be activated at the onset of myelination, suppresses branching and promotes coordinate progression of the myelin sheath around the axon. Thus, inhibition of ROCK in Schwann cells results in the formation of multiple myelin segments that independently wrap axons. ROCK appears to mediate these effects by promoting MLC phosphorylation, which is robustly activated at the onset of myelination and then downregulated. These findings have significant implications for mechanisms of myelin formation in Schwann cells and potentially oligodendrocytes and formation of axonal domains in myelinated fibers.

ROCK regulates Schwann cell branching and myelin morphology but not wrapping ROCK-inhibited Schwann cells form filopodial-like structures from their outer surface and generate variable numbers of myelin sheaths at their inner surface (Figs. $4 d, f, g, 6 c$ ). These effects were seen independently with two well characterized and selective ROCK inhibitors (Amano et al., 2000) underscoring the specificity of the results. ROCK mediates these effects primarily during 

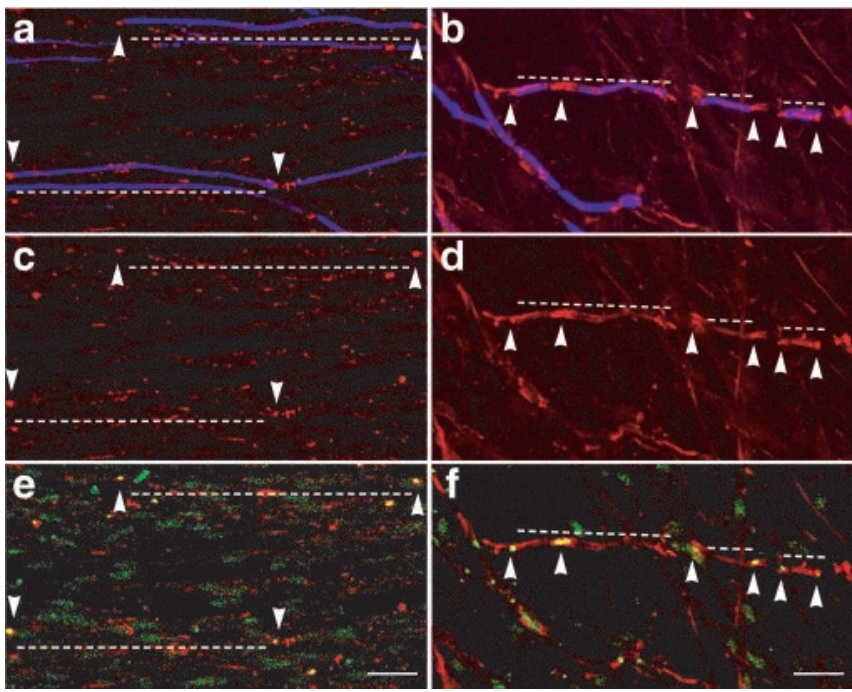

Figure 7. The distribution of ERM proteins is altered in ROCK-inhibited cultures. Confocal images of cocultures kept in myelinating media in media alone $(a, c, e)$ or supplemented with Y-27632 $(b, d, f)$ for $14 d$ were stained for MBP (blue) and ezrin (red) $(a-d)$ and $\beta \mathrm{IV}$ spectrin $(e, f$ green). In control cultures $(a, c, e)$, ezrin accumulates in processes at each end of the myelin segments (dashed line) that oppose nodes of Ranvier (indicated by arrowheads). In treated cultures $(b, d, f)$, ezrin staining is present at the nodal region (arrowheads) but also throughout the short internodes that form in such cultures (dashed lines), a feature never observed in control cultures. Colocalization of ezrin with $\beta$ IV spectrin at the node appears yellow in the merged images shown in $e$ and $f$. Ezrin staining from ensheathing $S c h w a n n$ cells is present in the background in both cases. Scale bar, $25 \mu \mathrm{m}$.

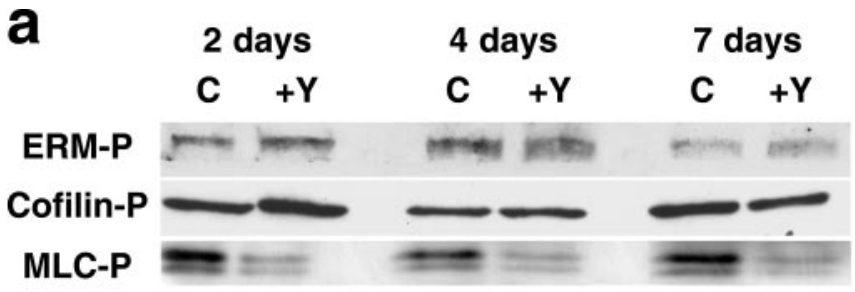

b

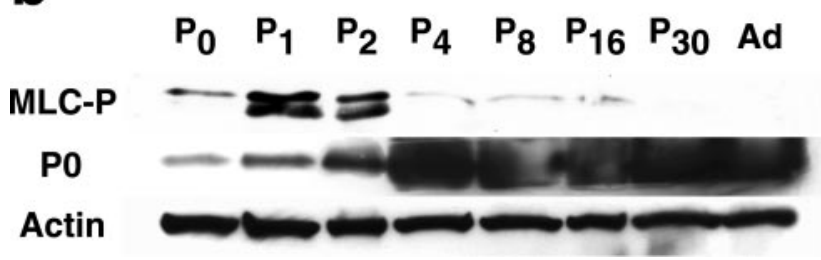

Figure 8. MLC phosphorylation in cocultures and during PNS development. $a$, Lysates of cocultures maintained in myelinating media for 2,4 , or $7 \mathrm{~d}$ with $(+Y)$ or without $(C)$ the ROCK inhibitor were analyzed for the phosphorylated forms of ERMs, cofilin, and MLC. Levels of phophorylated MLC were dramatically reduced in ROCK-inhibited cultures in contrast to cofilin and ERMs. $b$, Lysates ( $30 \mu \mathrm{g}$ of protein per lane) of rat sciatic nerve prepared from animals from $\mathrm{PO}$ to adult were probed with antibodies specific for phosphorylated MLC, P0, and actin. MLC phosphorylation is dramatically upregulated at the onset of myelination (P1-P2) and then rapidly declines.

formation of the initial membrane wrap, because both inhibitors had the greatest effect at the onset of myelination. A few examples of internal paranodes (e.g., paranodes underneath compact myelin) were observed in the treated cultures (Figs. 5b, 6c), suggesting that wrapping of the inner turn occasionally became discontinuous during active myelination. These findings implicate
ROCK in suppressing aberrant branching from the abaxonal (outer) surface and promoting the coordinate wrapping of the myelin sheath around the axon possibly by analogous suppression of aberrant branching of the inner adaxonal membrane. ROCK has a comparable role in other cell types, notably in neurons where it inhibits branching and outgrowth of axons and dendrites (Luo, 2002).

Schwann cells in the treated cultures exhibit some similarities to myelinating oligodendrocytes, notably in the increased numbers of processes and formation of multiple myelin segments. Segments formed by ROCK-inhibited Schwann cells appeared to vary in their thickness (Fig. $4 e-g$ ). Although EM will be necessary to confirm this impression, these results suggest each segment independently myelinates an axon akin to the ability of oligodendrocytes to generate sheaths with differing numbers of lamellae (Waxman and Sims, 1984). A recent study demonstrated that ROCK also regulates oligodendrocyte process formation (Wolf et al., 2001). Oligodendrocytes expressing a dominant-negative Rho had more elaborate processes, whereas those transfected with activated Rho had a striking reduction in the number and extent of process formation (Wolf et al., 2001). Although myelination was not directly investigated, these findings suggest that differences in the level of Rho activity in Schwann cells and oligodendrocytes could contribute to the distinct patterns of myelination by these glia; different activation levels may also account for variability in myelin segment numbers by oligodendrocytes in different regions of the CNS (Remahl and Hildebrand, 1990).

Note that Schwann cells extend along and wrap axons appropriately in the treated cultures. Even very short myelin segments had normal or even increased numbers of lamellae on the basis of immunofluorescence (Figs. $2 d, 4 d$ ) and electron microscopy (Fig. $5 a, b)$. These results indicate that key aspects of myelin morphogenesis (e.g., longitudinal extension along the axon and spiral wrapping) are ROCK-independent processes. They also support the notion that the molecular machinery that promotes spiral formation of the myelin sheath around the axon is dispersed along the length of the glial sheath rather than being localized to a few discrete sites.

\section{Regulation of ROCK activity during myelination}

ROCK appears to be activated at the onset of myelination. Thus, both MLC (Fig. 8b) and cofilin (data not shown) are robustly phosphorylated during the early postnatal period and then downregulated. Much of the phosphorylated MLC in early postnatal nerves is expressed by Schwann cells on the basis of immunofluorescence. ROCK inhibitors block MLC phosphorylation in cocultures much more effectively than MLC kinase inhibitors (data not shown) and have maximal effects at early stages of myelination. As ROCK levels remain stable or increase gradually over the first postnatal month (data not shown), the increase in MLC phosphorylation presumably reflects activation of ROCK and, by inference, Rho. In the future, it will be useful to demonstrate Rho activation directly as ROCK can be activated by certain lipids, including arachidonate, in a Rho-independent manner (Feng et al., 1999).

The mechanisms that regulate Rho activity in Schwann cells during myelination are not yet known. In the adult sciatic, RhoA is expressed in the abaxonal, paranodal, and microvillar compartments and Schmidt-Lanterman incisures (Scherer and Gutmann, 1996; Terashima et al., 2001). Localization of Rho to the abaxonal compartment suggests it may be regulated by ECM receptors. In agreement, laminin receptors were recently shown to activate Rho via the association of FAK (focal adhesion kinase) 
with p190Rho guanidine exchange factor (GEF) (Zhai et al., 2003). Interestingly, dystrophic mice, which harbor a mutation of the $\alpha$-2 chain of laminin (Sunada et al., 1994; Xu et al., 1994), exhibit myelin defects resembling those in kind, but not severity, to ROCK-inhibited cultures (Jaros and Bradley, 1979). Similarly, cocultures from dystrophic mice exhibit short, thick, myelin segments and nuclei that are eccentrically located along the internode (Okada et al., 1980) akin to treated cultures. These results suggest that laminin-2 may activate Rho to regulate Schwann cell myelination.

The rapid downregulation of phospho-MLC in vivo from approximately $\mathrm{P} 4-\mathrm{P} 14$ was unexpected, because this is a period when PNS myelin sheaths undergo significant expansion in the radial and longitudinal directions. However, the limited effect of ROCK inhibitors on older cultures is consistent with this finding. The mechanism by which Rho activity may be dowregulated after myelination is initiated is not known. p190 RhoGAP is a potential candidate, because it inhibits Rho activity in differentiating oligodendrocytes (Wolf et al., 2001). Additional studies will be important to clarify the role of both laminin and p190 as positive and negative regulators of Rho activity, respectively, during myelination.

\section{Role of ROCK in myelin sheath formation}

Movement of the glial sheath around the axon during myelination is likely to involve polarized actomyosin-generated forces linked to cell surface molecules that mediate interactions with the axon and matrix. How might ROCK coordinate progression of the myelin sheath around the axon and suppress aberrant branching during this process? Our data suggest that activation of Rho and ROCK at the onset of myelination results in MLC phosphorylation (Fig. 8). MLC phosphorylation, in turn, would be expected to promote actomyosin assembly, which is likely to exert contractile effects, such as those involving stress fibers or that limit spreading of the leading edge of cells (Wakatsuki et al., 2003), thereby limiting inappropriate branch formation. Data presented here (Fig. 2) and in a recent study (Taylor et al., 2003) indicate that formation of focal adhesions and stress fibers in Schwann cells indeed involves ROCK activity. MLC phosphorylation may also stabilize a continuous cortical actin network at the leading edge of the inner turn that prevents formation of separate myelin sheaths.

Myosin II has three isoforms, IIA, IIB, and the recently described (Golomb et al., 2004) IIC isoform. IIA and IIB are differentially localized and regulated in many cell types; much less is known about the IIC isoform. In neuronal growth cones, myosin IIB is localized at the periphery (Rochlin et al., 1995) and promotes growth cone extension (Bridgman et al., 2001) independent of MLC phosphorylation (Jalink et al., 1994; Wylie and Chantler, 2001). Myosin IIA is concentrated in the central domain (Rochlin et al., 1995) where it is essential for focal contacts and may promote neurite retraction in a Rho- and MLC phosphorylation-dependent manner (Wylie et al., 1998; Wylie and Chantler, 2001). Both oligodendrocytes (Song et al., 2001) and Schwann cells (C. V. Melendez-Vasquez, J. Salzer, unpublished observations) express these myosin isoforms. In oligodendrocytes, myosin IIB is enriched at the leading edge together with actin microfilaments, whereas myosin IIA is predominately in the perinuclear area and proximal region of the main processes (Song et al., 2001); their distribution has not yet been characterized in Schwann cells. Determination of the localization of these myosin isoforms and the regulation of their phosphorylation during Schwann cell myelination will be essential to elucidate the signal- ing pathways that coordinate glial wrapping as well as the ROCKindependent morphogenetic events of myelination, including spiral wrapping and longitudinal extension of the myelin sheath.

\section{Generation of axonal domains}

One of the most striking findings of this study is that each of the short MBP+ segments in the treated cultures constitutes a separate myelin-axon unit, complete with nodes and paranodes (Fig. 6). These nodal equivalents were remarkably closely spaced along the axon, in some cases being separated by $\sim 10 \mu \mathrm{m}$ or less. They accumulate in register with the gaps between short myelin segments, surrounded in many cases by paranodal markers. These results essentially confirm that the position of these channel clusters is not predetermined by the neuron but rather that the glial cell dictates their localization in agreement with previous studies (for review, see Salzer, 2003).

Of interest, nodal axonal markers were exclusively localized in the gaps between $\mathrm{MBP}+$ segments even though redistribution of ERM proteins, a marker of Schwann cell processes that project to the node (Melendez-Vasquez et al., 2001), was incomplete. Recent studies suggest that contact-dependant signals, potentially involving interactions of the axon with ERM + processes, are important in node formation (Ching et al., 1999; MelendezVasquez et al., 2001; Gatto et al., 2003). Findings in this study raise the possibility that nodes may also form as the result of active exclusion or endocytosis, of nodal components from sites overlain by compact myelin sheaths. However, because ezrin was frequently coexpressed by Schwann cells at many of the same sites as nodal markers (Fig. $7 f$ ), and glial processes frequently contact nodes (Fig. 5), these studies do not exclude a role for ERM+ processes in node formation. Other experimental strategies will be required to clarify the role of the nodal microvilli in node formation.

As noted, ERM proteins normally concentrate at either end of the Schwann cell before MBP expression, indicating Schwann cells are longitudinally polarized just before the onset of myelination (Fig. 7). Ezrin mislocalization in the ROCK-inhibited cultures may result from defects in the longitudinal organization of the treated Schwann cells and does not appear to result from a block in ERM phosphoryation, which was unaffected in these cultures (Fig. 8). Other manifestations of an aberrant longitudinal organization in the treated Schwann cells include an eccentric location of the nucleus and multiple, short myelin segments that form along the length of the Schwann cell. Rho and ROCK have been implicated in the development of epithelial polarity via transport and cytoskeletal effects (Van Aelst and Symons, 2002). Thus, defects in ERM localization and longitudinal organization may potentially reflect broader defects in cell polarity.

In summary, we have shown that ROCK activation regulates the initial morphogenesis of the myelin sheath and suggest that MLC phosphorylation, which increases dramatically but transiently at the onset of myelination, plays a key role in these events. These studies, and the recent demonstration that a mutation in a RhoGEF is associated with thinly myelinated nerve fibers (VeRhoeven et al., 2003), underscore the importance of Rho family GTPases in myelination. Elucidating the regulation of Rho activity, the function of ROCK-independent myosin motors, and the role of other Rho GTPases during myelination should provide important, additional insights into mechanisms of myelin formation. 


\section{References}

Amano M, Ito M, Kimura K, Fukata Y, Chihara K, Nakano T, Matsuura Y, Kaibuchi K (1996) Phosphorylation and activation of myosin by Rhoassociated kinase (Rho-kinase). J Biol Chem 271:20246-20249.

Amano M, Chihara K, Nakamura N, Kaneko T, Matsuura Y, Kaibuchi K (1999) The $\mathrm{COOH}$ terminus of Rho-kinase negatively regulates Rhokinase activity. J Biol Chem 274:32418-32424.

Amano M, Fukata Y, Kaibuchi K (2000) Regulation and functions of Rhoassociated kinase. Exp Cell Res 261:44-51.

Asou H, Hamada K, Miyazaki T, Sakota T, Hayashi K, Takeda Y, Marret S, Delpech B, Itoh K, Uyemura K (1995) CNS myelinogenesis in vitro: time course and pattern of rat oligodendrocyte development. J Neurosci Res 40:519-534.

Bridgman PC, Dave S, Asnes CF, Tullio AN, Adelstein RS (2001) Myosin IIB is required for growth cone motility. J Neurosci 21:6159-6169.

Bunge RP, Bunge MB, Bates M (1989) Movements of the Schwann cell nucleus implicate progression of the inner (axon-related) Schwann cell process during myelination. J Cell Biol 109:273-284.

Chew TL, Masaracchia RA, Goeckeler ZM, Wysolmerski RB (1998) Phosphorylation of non-muscle myosin II regulatory light chain by p21activated kinase (gamma-PAK). J Muscle Res Cell Motil 19:839-854.

Ching W, Zanazzi G, Levinson SR, Salzer JL (1999) Clustering of neuronal sodium channels requires contact with myelinating Schwann cells. J Neurocytol 28:295-301.

Davies SP, Reddy H, Caivano M, Cohen P (2000) Specificity and mechanism of action of some commonly used protein kinase inhibitors. Biochem J 351:95-105.

Edwards DC, Sanders LC, Bokoch GM, Gill GN (1999) Activation of LIMkinase by Pak1 couples Rac/Cdc42 GTPase signalling to actin cytoskeletal dynamics. Nat Cell Biol 1:253-259.

Einheber S, Hannocks MJ, Metz CN, Rifkin DB, Salzer JL (1995) Transforming growth factor-beta 1 regulates axon/Schwann cell interactions. J Cell Biol 129:443-458.

Etienne-Manneville S, Hall A (2002) Rho GTPases in cell biology. Nature 420:629-635.

Feng J, Ito M, Kureishi Y, Ichikawa K, Amano M, Isaka N, Okawa K, Iwamatsu A, Kaibuchi K, Hartshorne DJ, Nakano T (1999) Rho-associated kinase of chicken gizzard smooth muscle. J Biol Chem 274:3744-3752.

Fernandez-Valle C, Gorman D, Gomez AM, Bunge MB (1997) Actin plays a role in both changes in cell shape and gene-expression associated with Schwann cell myelination. J Neurosci 17:241-250.

Gatto CL, Walker BJ, Lambert S (2003) Local ERM activation and dynamic growth cones at Schwann cell tips implicated in efficient formation of nodes of Ranvier. J Cell Biol 162:489-498.

Geren BB (1954) The formation from the Schwann cell surface of myelin in the peripheral nerves of chick embryos. Exp Cell Res 7:558-562.

Golomb E, Ma X, Jana S, Preston Y, Kawamoto S, Shoham NG, Goldin E, Conti MA, Sellers JR, Adelstein RS (2004) Identification and characterization of nonmuscle myosin II-C, a new member of the myosin II family. J Biol Chem 279:2800-2808.

Huxley AF, Stämpfli R (1949) Evidence for saltatory conduction in peripheral myelinated nerve fibers. J Physiol (Lond) 108:315-339.

Ikebe M, Hartshorne DJ, Elzinga M (1986) Identification, phosphorylation, and dephosphorylation of a second site for myosin light chain kinase on the 20,000-dalton light chain of smooth muscle myosin. J Biol Chem 261:36-39.

Ishizaki T, Uehata M, Tamechika I, Keel J, Nonomura K, Maekawa M, Narumiya S (2000) Pharmacological properties of Y-27632, a specific inhibitor of Rho-associated kinases. Mol Pharmacol 57:976-983.

Jalink K, van Corven EJ, Hengeveld T, Morii N, Narumiya S, Moolenaar WH (1994) Inhibition of lysophosphatidate- and thrombin-induced neurite retraction and neuronal cell rounding by ADP ribosylation of the small GTP-binding protein Rho. J Cell Biol 126:801-810.

Jaros E, Bradley WG (1979) Atypical axon-Schwann cell relationships in the common peroneal nerve of the dystrophic mouse: an ultrastructural study. Neuropathol Appl Neurobiol 5:133-147.

Kachar B, Behar T, Dubois-Dalcq M (1986) Cell shape and motility of oligodendrocytes cultured without neurons. Cell Tissue Res 244:27-38.

Kimura K, Ito M, Amano M, Chihara K, Fukata Y, Nakafuku M, Yamamori B, Feng J, Nakano T, Okawa K, Iwamatsu A, Kaibuchi K (1996) Regulation of myosin phosphatase by Rho and Rho-associated kinase (Rho-kinase). Science 273:245-248.
Luo L (2002) Actin cytoskeleton regulation in neuronal morphogenesis and structural plasticity. Annu Rev Cell Dev Biol 18:601-635.

Maekawa M, Ishizaki T, Boku S, Watanabe N, Fujita A, Iwamatsu A, Obinata T, Ohashi K, Mizuno K, Narumiya S (1999) Signaling from Rho to the actin cytoskeleton through protein kinases ROCK and LIM-kinase. Science 285:895-898.

Matsui T, Yonemura S, Tsukita S (1999) Activation of ERM proteins in vivo by Rho involves phosphatidyl-inositol 4-phosphate 5-kinase and not ROCK kinases. Curr Biol 9:1259-1262.

Matsuoka Y, Li X, Bennett V (2000) Adducin: structure, function and regulation. Cell Mol Life Sci 57:884-895.

Maurel P, Salzer JL (2000) Axonal regulation of Schwann cell proliferation and survival and the initial events of myelination requires PI 3-kinase activity. J Neurosci 20:4635-4645.

Melendez-Vasquez CV, Rios JC, Zanazzi G, Lambert S, Bretscher A, Salzer JL (2001) Nodes of Ranvier form in association with ezrin-radixin-moesin (ERM)-positive Schwann cell processes. Proc Natl Acad Sci USA 98:1235-1240.

Mermall V, Post PL, Mooseker MS (1998) Unconventional myosins in cell movement, membrane traffic, and signal transduction. Science 279:527-533.

Okada E, Bunge RP, Bunge MB (1980) Abnormalities expressed in longterm cultures of dorsal root ganglia from the dystrophic mouse. Brain Res 194:455-470.

Oshiro N, Fukata Y, Kaibuchi K (1998) Phosphorylation of moesin by Rhoassociated kinase (Rho-kinase) plays a crucial role in the formation of microvilli-like structures. J Biol Chem 273:34663-34666.

Pedraza L, Huang JK, Colman DR (2001) Organizing principles of the axoglial apparatus. Neuron 30:335-344.

Peters A, Palay SL, Webster HD (1991) The fine structure of the nervous system, Ed 3, pp 212-264. New York: Oxford UP.

Previtali SC, Feltri ML, Archelos JJ, Quattrini A, Wrabetz L, Hartung H (2001) Role of integrins in the peripheral nervous system. Prog Neurobiol 64:35-49.

Remahl S, Hildebrand C (1990) Relation between axons and oligodendroglial cells during initial myelination: I. The glial unit. J Neurocytol 19:313-328.

Riento K, Ridley AJ (2003) Rocks: multifunctional kinases in cell behaviour. Nat Rev Mol Cell Biol 4:446-456.

Rios JC, Melendez-Vasquez CV, Einheber S, Lustig M, Grumet M, Hemperly J, Peles E, Salzer JL (2000) Contactin-associated protein (Caspr) and contactin form a complex that is targeted to the paranodal junctions during myelination. J Neurosci 20:8354-8364.

Rochlin MW, Itoh K, Adelstein RS, Bridgman PC (1995) Localization of myosin II A and B isoforms in cultured neurons. J Cell Sci 108:3661-3670.

Rodriguez OC, Schaefer AW, Mandato CA, Forscher P, Bement WM, Waterman-Storer CM (2003) Conserved microtubule-actin interactions in cell movement and morphogenesis. Nat Cell Biol 5:599-609.

Salzer JL (1995) Mechanisms of adhesion between axons and glial cells. In: The axon (Waxman S, Kocsis J, Stys P, eds), pp 164-184. New York: Oxford UP.

Salzer JL (2003) Polarized domains of myelinated axons. Neuron 40:297-318.

Scherer SS, Gutmann DH (1996) Expression of the neurofibromatosis 2 tumor suppressor gene product, merlin, in Schwann cells. J Neurosci Res 46:595-605.

Song J, Goetz BD, Baas PW, Duncan ID (2001) Cytoskeletal reorganization during the formation of oligodendrocyte processes and branches. Mol Cell Neurosci 17:624-636.

Sunada Y, Bernier SM, Kozak CA, Yamada Y, Campbell KP (1994) Deficiency of merosin in dystrophic $d y$ mice and genetic linkage of laminin M chain gene to $d y$ locus. J Biol Chem 269:13729-13732.

Tan JL, Ravid S, Spudich JA (1992) Control of nonmuscle myosins by phosphorylation. Annu Rev Biochem 61:721-759.

Taylor AR, Geden SE, Fernandez-Valle C (2003) Formation of a betal integrin signaling complex in Schwann cells is independent of Rho. Glia 41:94-104.

Terashima T, Yasuda H, Terada M, Kogawa S, Maeda K, Haneda M, Kashiwagi A, Kikkawa R (2001) Expression of Rho-family GTPases (Rac, cdc42, RhoA) and their association with p-21 activated kinase in adult rat peripheral nerve. J Neurochem 77:986-993.

Topilko P, Levi G, Merlo G, Mantero S, Desmarquet C, Mancardi G, Charnay 
P (1997) Differential regulation of the zinc finger genes Krox-20 and Krox-24 (Egr-1) suggests antagonistic roles in Schwann cells. J Neurosci Res 50:702-712.

Trapp BD, Andrews SB, Wong A, O’Connell M, Griffin JW (1989) Colocalization of the myelin-associated glycoprotein and the microfilament components, F-actin and spectrin, in Schwann cells of myelinated nerve fibres. J Neurocytol 18:47-60.

Tsuji T, Ishizaki T, Okamoto M, Higashida C, Kimura K, Furuyashiki T, Arakawa Y, Birge RB, Nakamoto T, Hirai H, Narumiya S (2002) ROCK and mDial antagonize in Rho-dependent Rac activation in Swiss 3T3 fibroblasts. J Cell Biol 157:819-830.

Van Aelst L, Symons M (2002) Role of Rho family GTPases in epithelial morphogenesis. Genes Dev 16:1032-1054.

VeRhoeven K, De Jonghe P, Van de Putte T, Nelis E, Zwijsen A, Verpoorten N, De Vriendt E, Jacobs A, Van Gerwen V, Francis A, Ceuterick C, Huylebroeck D, Timmerman V (2003) Slowed conduction and thin myelination of peripheral nerves associated with mutant Rho Guanine-nucleotide exchange factor 10. Am J Hum Genet 73:926-932.

Wakatsuki T, Wysolmerski RB, Elson EL (2003) Mechanics of cell spreading: role of myosin II. J Cell Sci 116:1617-1625.

Waxman SG, Sims TJ (1984) Specificity in central myelination: evidence for local regulation of myelin thickness. Brain Res 292:179-185.
Wilson R, Brophy PJ (1989) Role for the oligodendrocyte cytoskeleton in myelination. J Neurosci Res 22:439-448.

Winckler B, Forscher P, Mellman I (1999) A diffusion barrier maintains distribution of membrane proteins in polarized neurons. Nature 397:698-701.

Wolf RM, Wilkes JJ, Chao MV, Resh MD (2001) Tyrosine phosphorylation of p190 RhoGAP by Fyn regulates oligodendrocyte differentiation. J Neurobiol 49:62-78.

Wylie SR, Chantler PD (2001) Separate but linked functions of conventional myosins modulate adhesion and neurite outgrowth. Nat Cell Biol 3:88-92.

Wylie SR, Wu PJ, Patel H, Chantler PD (1998) A conventional myosin motor drives neurite outgrowth. Proc Natl Acad Sci USA 95:12967-12972.

Xu H, Christmas P, Wu X-R, Wewer UM, Engvall E (1994) Defective muscle basement membrane and lack of M-laminin in the dystrophic $d y / d y$ mouse. Proc Natl Acad Sci USA 91:5572-5576.

Zhai J, Lin H, Nie Z, Wu J, Canete-Soler R, Schlaepfer WW, Schlaepfer DD (2003) Direct interaction of focal adhesion kinase with p190RhoGEF. J Biol Chem 278:24865-24873.

Zorick TS, Syroid DE, Arroyo E, Scherer SS, Lemke G (1996) The transcription factors SCIP and Krox-20 mark distinct stages and cell fates in Schwann cell differentiation. Mol Cell Neurosci 8:129-145. 